\title{
ARCHITECTURE ACADEMIC BY INFORMATION TECHNOLOGIES UTILIZATION
}

\author{
S. A. Hosseini ${ }^{1, *}$, S. Teimory ${ }^{2}$, K. Loloie ${ }^{3}$ and M. R. A. Hamedani ${ }^{4}$ \\ ${ }^{1}$ Master of Architecture, Islamic Azad University of Mahallat branch \\ ${ }^{2}$ Tehran University, invited in Islamic Azad University of Saveh \\ ${ }^{3} \mathrm{PhD}$ in art history, scientific board member of Islamic Azad University of Mahallat branch \\ ${ }^{4} \mathrm{PhD}$ in Architecture, Lecturer in Islamic Azad University of Mahallat branch
}

Published online: 15 May 2016

\begin{abstract}
This research aims at studying teaching modern architecture with information technology approach. Today, information technology is used to transmit knowledge in many universities of the world. Information technology tools are potentially capable of providing engineering students with a broad continuum of curriculum in order to produce and connect ideas and decrease the gap between understanding and accepting innovations. Contemporary universities are prone to a critical changes, one of which being new educational needs. In recent years, many countries owe their development to the improvement of communication and information tools. Architecture education is very critical and therefore new educational needs are realized more in this field compared to other fields. That's because architecture education has artistic feature and art education requires reflective contexts, modern technology and novice educational tools in order to foster students' creativity and reinforce their visualization ability. Information technology has an important role in this process. On the other hand, architecture is a multidisciplinary field with specific requirements that are important to be regarded and put in to priority in architecture education.
\end{abstract}

Author Correspondence, e-mail: asghar.hosseini2000@gmail.com

doi: http://dx.doi.org/10.4314/jfas.v8i3s.161

Journal of Fundamental and Applied Sciences is licensed under a Creative Commons Attribution-NonCommercial 4.0

International License. Libraries Resource Directory. We are listed under Research Associations category. 
Accordingly, the present research studies architecture education; the impact of information technology on agriculture education; and its contribution to the reflectivity of educational context, which is one of requirements of architecture education. We then focus on different aspects of information technology and its effects in educational contexts and contribution to educational improvement. Next, we introduce new educational tools in the era of technology that has proposed a new trend in education. The result of this study proves the necessity of applying information technology in architecture education and of providing required basis to use these tools in order for students' creativity and visualizations abilities to be fostered and reinforced in architecture designs.

Keywords: Academic; architecture; information technology.

\section{INTRODUCTION}

Today, information technology in various cultural, economic, political spheres of society had an impact and its impact on cultural and educational spheres is very important because the fundamental areas of community promotion are cultural and educational spheres. According to the power of digital technology and the spread of information, higher education is on the verge of a revolution. In the information age will require learning spaces with more different characteristics and implementation of new training methods will changes the learning environment which design of learning environment must be tailored to the need of modern education. Educational environment plays a major role in the learning process of providing different needs. The development of many countries in recent years thanks to the development of information and communication tools (Motlagh and Behrooznia, 1388). An educational space is one of the areas of environmental architecture that play a major role in a community. The role of education in development of a society is undeniable. Neglect and ignorance in the design of educational facilities in many countries have shown their undesirable results (Kaamelnia, 1388). Understanding of the environment has been done through perception of spatial quality and this quality can affect spatial perception and can improve it, so whatever these environment has more richness in terms of quality, they can establish more appropriate relationship with the beneficiaries in addition to better implied teaching (MazidiI and Fatahi Abarqhove, 1390). The role of information technology in education has increased significantly. Decisive role of information technology in education by the Ministry of Education clearly recognized that 
advanced teaching technology and learning have been identified as an important goal of the strategy of education between 1997 and 2004 (Hwa Hu, 2003, 228) early attempts to develop information technology in higher education, has been done in the twentieth century. Now universities are faced with the new evolution of information technology which its capabilities are much deeper than in the past. The spread of information technology has the potential capacity to reshape quality of learning in universities and colleges (Rahmanpour and others, 1388). The use of this advanced technology in architectural teaching has high impact in improving its educational quality. To the efficiency of information technology abilities in architectural teaching, is necessary to teaching features based on information technology and different aspects and its impact on the learning environment to be monitored.

\section{RESEARCH METHODOLOGY}

Research method is analytical descriptive. This study consider to examination of architecture education and concepts of information technology and its features and its impact on education, appropriate strategies to improve architecture engineering education using modern education technology, changes in the educational space and flexibility resulting from use of information technology tools and finally the training methods in electronic spaces and architecture reduction.

\section{BACKGROUND OF RESEARCH}

In the case of the impact of using information technology in various fields, especially in the field of education in different disciplines including architecture has been a lot of research. (Farajollahi and Zarif Sanayei, 1388): In a study entitled "learning based on Information and Communication Technology in higher education" has addressed the diverse needs of each society in the information age and the results indicate that the Information Technology transform the paradigm of education and is enriched the available training models and create new ways that learners have an active role and has been stressed to flexible, independent and interacting learning. (Farhadi Robabeh 1382): In a study "electronic learning as a new paradigm in the information age" it been discussed to a lot of functionality of this educational system, providing infrastructure to use it and necessary of applying it. (Mahmudi and Taqi Zadeh, 1388): In a study entitled "Information Technology and evolution of architectural teaching" has been considered to the evolution of 
practical training tools and the role of Information Technology as a new educational tool which due to the art nature of architecture branch, information technology tools is a fundamental device of architectural education. (Taqi Zadeh, Mahmudi, 1390): In a study entitled "The Role of virtual learning and the Internet in the process of architectural education" is addressed to the importance of virtual education in architecture branch. The capability quick and easy information transferring which provides Internet, is well absorbed the school system. Education of architecture especially since the 1990s with distance education programs in an integrated better way, as a virtual studio is adapted his design. Creating virtual studio of architecture schools designing has strengthened more than before. Because of that architecture is always connected with the latest technology and information, such as a fantastic opportunity not to be missed. In the design process, will be looking for ways in which, unlike conventional methods, can help students to unlocking their latent talents to be in higher creativity in designing and innovation. Design thinking and intellectual contexts charge during the design process, including topics which could have a direct role in improving the formation of architectural design patterns (Hosseini, 1393).

All accomplished studies indicate the importance of using information technology in the information age that with every day progress of the technology its importance has been added.

\section{EDUCATION OF ARCHITECTURE}

Architecture is the reflecting of concepts and values that begins from its training (Vafamehr, 1390). Onat knows the education of architecture as a system of efforts which must be done separately in order to obtain necessary behavioral development that has been imposed by the profession architecture. This change in behavior should be achieved through personal experience (Kurt, 2009, 402). One of our educational goals, especially in the fields of architecture, is the art of creativity power research and sense of self-esteem. In the architecture education should be considered to Independence in way and creativeness that is the most basic characteristics of architecture (Adibi, 1382). The first teacher of young architects is their surrounding areas: Such as educational areas. The impact of spaces in teaching and learning process is certain. The use of advanced technology and modern technology in architectural engineering education can lead to new approaches in education. Architectural engineering field has an artistic nature, and to develop students' creativity and visualization require new tools and educational technology. Information technology with making flexible spaces and innovative educational tools and 
intelligent training environment provides the facilities for architectural engineering education promotion.

\section{INFORMATION TECHNOLOGY AND TRAINING}

Information technology consists of two components of technology and information. There have been various definitions for both terms that one of the definitions is sufficient. Technology is the application of science to industry using procedures and regular and arrow studies. Information is all the ideas, facts and creative of mind that it be registered, published or distributed official or unofficial and any state and may be documented or undocumented (Fathian and Mahdavi Nour, 1389 ). Also Information technology has other different definitions which the most important ones are:

The term of information technology includes a set of techniques and tools for optimizing and supporting the active systems with centrality of information and knowledge. It also includes the study, design, development, implementation, maintenance and management of computer-based information systems and particularly applications of computer software and hardware. In other words, to describing technologies that is used and helps the man in recording, storing, processing, retrieving, transmitting and receiving information. This so-called new technology is covered computers, transmission by fax, micrographs, telecommunications, microelectronics and also older technology such as document filing systems, mechanical computing machines, printing and engraving (Mahmoudi and Taghi Zadeh, 1388).

Information technology is a general term that is used to broaden the innovation of telecommunication and computer products and electronic services (Fathian, 1387). The use of new information technologies brings new potential in technology-based education which taking advantage of them in the teaching-learning process is very effective. These technologies have also led to lifelong learning is used wide and deep. "The facts show that the use of new technologies in the 21st century will have a profound impact on human social life and education and education is certainly not exempt from these changes. Research in education, states the article that information technology has been mainly used in regular education system "(Mahmoudi and Nalchygar, 1387). With the emergence of technology, a challenging policy has been created at all levels of higher education and especially architectural education (Taghizadeh, M., 1390). 
With the introduction of computers and telecommunications and thus make sense of distance, spaces and physical locations and their definitions, just like human faces, have changed over time. For example, meeting and conferences rooms have taken virtual shape. Because many of the elements and their physical components, have been replaced by computers. (Hosseini and Loloie, 1394).

\section{IMPACT OF INFORMATION TECHNOLOGY ON ARCHITECTURE EDUCATION}

Today in many universities of world the use of information technologies is used for knowledge transfer with regard to its unlimited and inexhaustible potential. Information technology tools have the internal capability to offer a wide range of lesson plans to produce and communicate ideas and to cover the gap between the understanding and acceptance of innovation for engineering students (Mousavi and others, the 1390). Now the use of new technology in architectural education is developing day by day. With a comprehensive insight into modern systems, new methods, features and advanced tools which has an important role in the field of architecture education, architectural education will be upgraded. Information technology can help to modern education needs. In architectural engineering education, the question arises whether the use of computers and new educational tools lead to promote creativeness of thinking which eventually will be end by ideas to create a building?

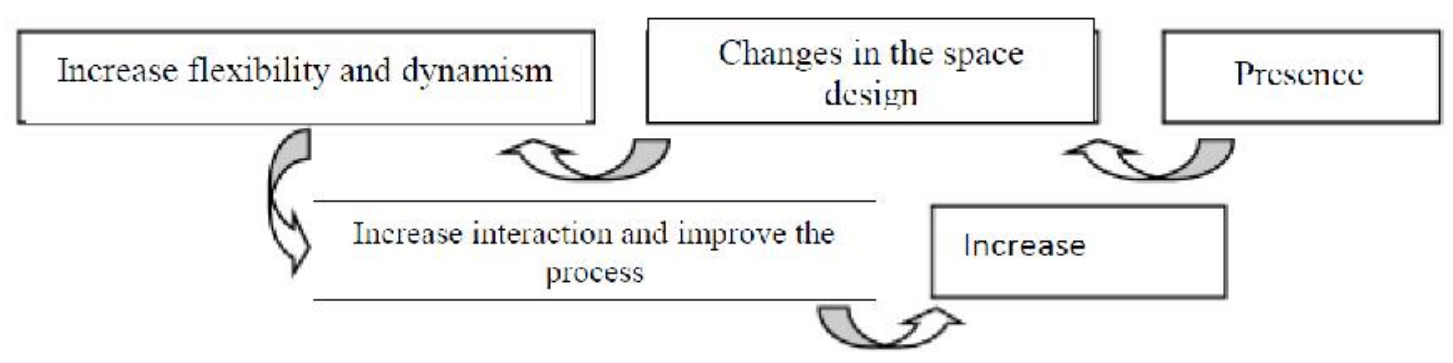

Fig.1. The impact of technology in education (Writer)

Use of information technology in architecture education lead to create dynamic flexible and smart spaces. Flexible spaces in architecture field can relieve the problem of courses that are taught common theoretical and practical and needs to separate spaces. Flexible spaces has possibility of increasing social interaction and taking part in group activity and transferring thought that would be required to any discipline, especially discipline of art education. 
Adoption of information technology needs in the field of architectural as the main tool of education.

Learning architecture and how to use information technology at the same level.

Adoption of newer tools of information technology for the evolution of architecture engineering education.

Identifying of optimal strategies for relationship between architecture knowledge and art in the periods before and after information technology.

Conversion of cultural invasion to cultural exchange opportunities in the Iranian Architects Engineering.

Using the training modern methods as a new approach to increase student creativity.

Flexibility in learning environment, enabling students to participate in class discussions.

The possibility of sharing knowledge and use of online global classes in class with attended the master

Chart 2. IT-based architecture training purposes, (Alam Rassi, 1391)

\section{IT COMMUNICATION AND ITS IMPACT IN A FLEXIBLE LEARNING ENVIRONMENT}

Flexibility, the ability to connect the physical environment to users regardless of their ability (KamelNia, 1388). Teaching is dynamic and as a result learning spaces should be able to fulfill the requirements based on the changing in training patterns and with advances in technology and demand of students and teachers has been increased every day and educational spaces should be possible to provide this flexibility and meet their sustainability over time (Mahmoudi, 1390).

\section{DIFFERENT SPECIES OF FLEXIBILITY}

Pena and Parshal in their book on architectural planning have accounted flexibility including multi-functional features of architecture, variability in the interior spaces and its exterior scalable and believe that each of these concepts alone cannot be replaced by the concept of flexibility. Variability (multi-functional space) 
Variability is the ability to provide different uses of space. This kind of flexibility is dealing with two variables: time and space. Educational spaces can use for simultaneously being multifunctional and for different functions at different times (in the future).

\section{Integrating Vulnerability}

Versatility is the ability to adapt between a space and new required circumstances. This ability causes to fluctuating in internal components and the possibility of their various combining. Versatility in teaching spaces can be very efficient and economically very affordable. Because in the coming years, the need for educational facilities (such as schools and high schools) is variable and the space can be optimized with versatility or mobility of spaces, for example, social hall yard (sporting space) in the seasons can be extremely effective.

\section{Variability (differentiation and integration)}

In flexible learning spaces design, variability means the ability to respond to growth of areas at different stages of training. In other words this ability can make possible the changing the size to smaller or larger. This variability may be happen due to long-term or short-term needs "(Mahmudi, 1390).

Information technology will change the interior space of educational spaces and with flexibility of space the need for different learning spaces at different times will be resolved.

Scientific and technical progress put more advanced tools at the disposal of training. Wilbur Schramm is characterized four generations in the history of the development; Characteristic of these four generations is presence and growing involvement of machine. At the first-generation the presence of teacher is accomplisher. (He used Flat Black, objects, paintings and drawings to complete her/his lesson). In the second generation starts with the invention of printing, machine helps to book production. In the third generation, machine expanded amount of vision and hearing:

TV Pictures, tape recorder and radio. In the fourth generation connection is established directly between man and machine. Such as training programs, education, linguistics, computer.

In the present era newest theory seeks to find the best argument in learning activities. The aim of educate, is not giving solutions, but is educate of thinking ways which is based on the logic of mathematic, looking to dominate to very diverse situations and machine can be very helpful (Mahmoudi 0.1390). 
Today, when we talk about educational technology, more we mean the benefit of education from modern information and communication technologies in all areas from education of children to educate adults for people training. None of these features are not used alone, but always are combined with other sources such as reading literatures, discussion groups, correspondence training (Mahmoudi, 1390).

The mean of information technology is applying not in person and semi-person ways which provides the flexibility of the learning environment, educational facilities or training facilities. Without a doubt, in this method space of classroom is decreased and should be added to the teaching aids facilities. In teaching method by use of information technology instead of desks and blackboards in classes the monitor, computer desktop and a fast line internet and new digital tools is used which cause to changes in the educational space that has an important role in enhancing the learning process.

\section{IT communication and its impact in learning environment flexibility}

Today, the integration of ICT in education, is widely accepted from educational system around the world and also it seems that the movements of engineering education institutions to take advantage of new information and communication technologies in teaching and learning process is one of required and basic steps for learning environments. Because this technology provides a lot of facilities in general for all sections of society and in particular for some groups with special situations and certain restrictions. In this context, many changes have taken place in higher education and basic actions have taken in architecture education around the world. The use of modern educational tools in learning process: such as aibords [4], video projector, using online systems, digital tools to design and sketch called Leap Motion [4], graphic software and digital plates are widely growing and has large effect on improving the education of architecture. Using these tools make changes in the educational process.

Information technology transforms spatial structure of educational facilities and present new trends in education. One of these changes is in the design of educational spaces which with design changes of the space course layout and its interior design also will changed and spaces become usable for theoretical and practical courses of architecture, classes and studios have a multipurpose use. In addition with changes in the environment the teaching and learning process will change. Participation of students in theoretical and practical discussions in these spaces will increase which is required for student learning. So teaching hasn't one-dimensional aspect. In 
modern education system, student participation has more increased and the role of teacher becomes paler. In other words the use of modern tools of education, cause to significant changes in the architectural design process which is an important architectural course. Using these tools alongside traditional tools of architectural design in addition to accelerating the design process, increase creativity of students. Using a variety of graphic software, digital plates and Leap motions have a significant impact in the field.

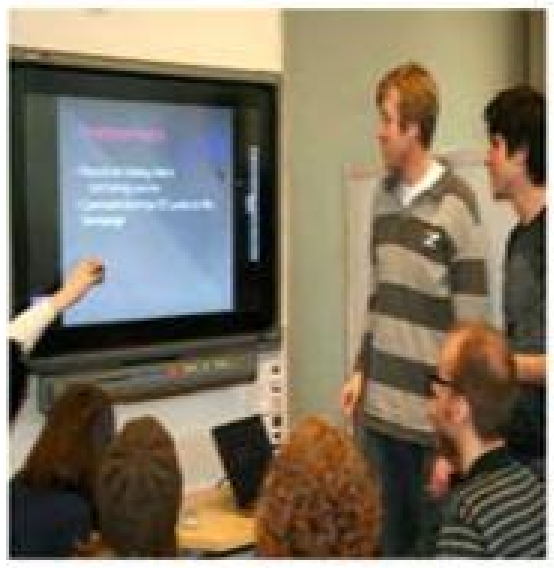

Fig.2. Collaboration ( www.edu.com)

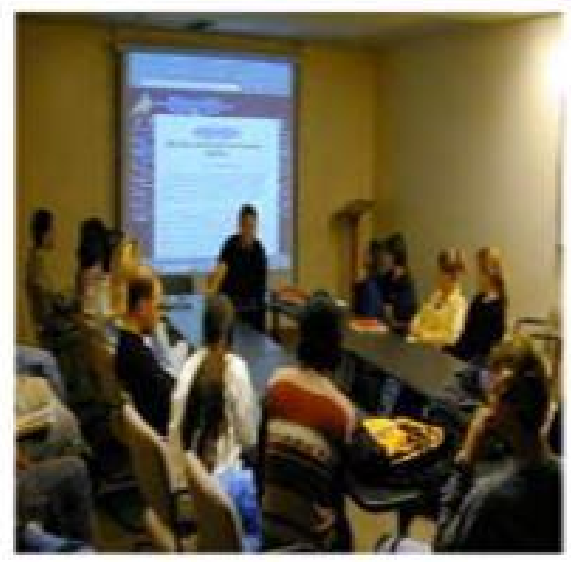

Fig.3. Collaboration (cusb.edu.com)

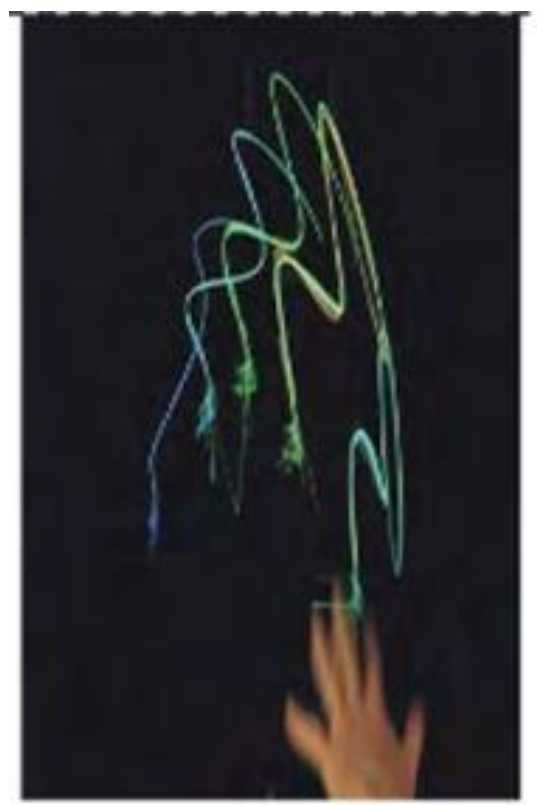

Fig.4. Accelerating the design process

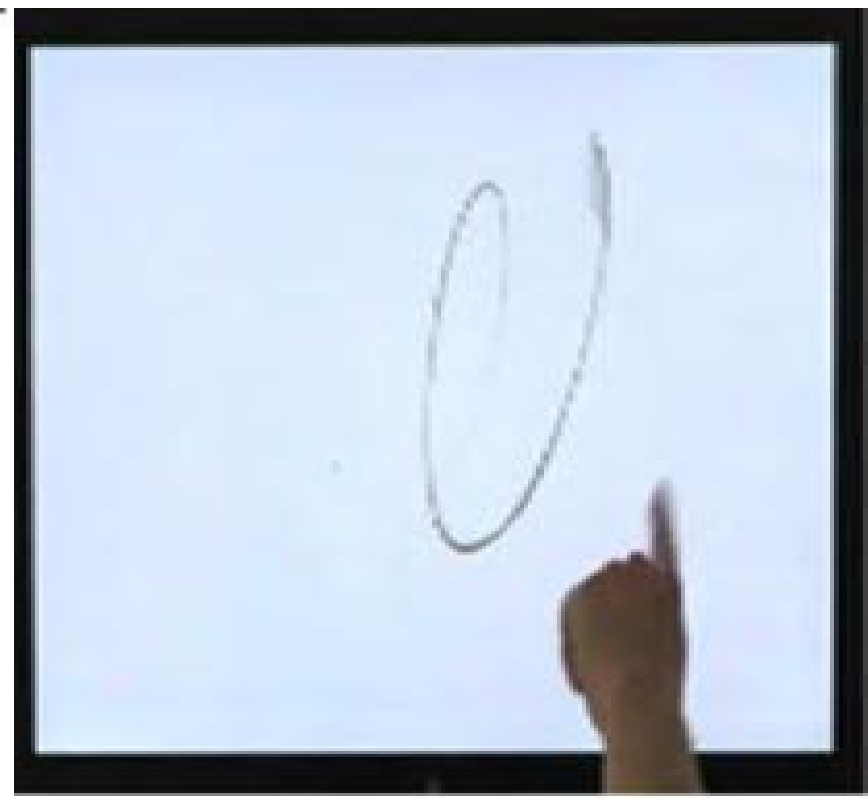

Fig.5. Increase creativity (online.xsj.com) 


\section{VARIETY OF TRAINING METHODS IN ELECTRONIC SPACES}

In addition to the mentioned changes new technology has created variations in teaching methods. Educational system type and how to use information technology in it offers broad definition of the impact of information technology in flexibility. In this section, three types of training methods in the electronic space have been mentioned.

- Presence with information technology and training aids facilities

- Semi-presence with information technology and training aids facilities

- Non presence just with information technology facilities

- Presence with information technology and training aids facilities

In this education type which presence of learner and teacher in a particular place and time is essential and is used in many universities. In this type of learning is used environment (classroom), training facilities or flexible spaces that training facilities have provided. In this style of training in the field of architecture students with a physical presence in the studio are used educational facilities and up to date technology.

Semi-presence with information technology and training aids facilities

Semi-presence training is to organize the teaching - learning process, so that each educational center is mighty in the selection and application solutions using one or more types of learning materials, media and other means of mass communication ability. In this type of training, the use of information technology facilitates the learning process with participation of learners. In the non-presence or half-presence method educational spaces have decreased and facilities and teaching aids will be increased.

Non presence just with information technology facilities

Telepresence notes to interact in real time. With aid of on-line communication tools such as interactive TV, video networking, audio and video conferencing, virtual classroom presence of mind is provided. Telepresence can be motivating for learners. Hyphe and Coze have examined the impact of online communication on improving students' critical thinking skills and motivating in a study and found providing feedback at the same time, motivate students to participate in activities and cause to improve communication skills and express ideas (Farajollahi and Zarif Sanayei, 1388).

Some of the features of distance learning include: 
Separation of teacher and learner from each other, both geographically and in terms of time.

$>$ Use of technology in education using new equipment and various educational media.

$>$ Learning different from the traditional form in the class (regardless of hours of collective bug fixes).

Teacher participation in new forms of learning - teaching process as a main factor.

$>$ Individualization and privatization learning, which means that in this system learner is determiner of the time and place song of learning commensurate with the talents.

Interests and in general abilities are their personal characteristics (Fathian and Mahdavi noor, 1389). In many institutions are trying to forming infrastructure required for distance education programs outside of the schools of architecture and architectural education is also equipped with this new form to define its role within the context of global changes. Today's distance learning programs have begun to open its place in the teaching and learning curriculum of universities or at least the possibility of such a program has been started and is discussed. But the main problem related to architectural teaching is practical courses and workshops that are difficult to transfer them to the online form. Given that the architectural design studios are located in the center of architectural education, perhaps is the point of distance education and presence and group training. Some architectural schools prefer that uses a combination of teaching methods which in such a way beside the real design studios, students can use the Internet too. Architectural design studios are located in the center of architectural education. Through programs, projects, criticisms inside the studio, language and behavior learned in the workshop of architectural, cultural context of specialization are formed in architectural students. After this process, to providing sufficient space for real physical studio, designing system in studio is used (Taghizadeh and Mahmoodi, 1390). So for architectural education, which is artistic education, especially in design part that is center of architecture education, physical presence, is very effective in the educational process and with it, the Internet can be used to communicate with the world's teachers as well as for communicate and training in different universities at the same time.

\section{CONCLUSION}

Now the use of new technology in architectural education is developing day by day. With a comprehensive insight into modern systems of modern methods, features and advanced tools 
which has an important role in the field of architecture education, architectural education will be upgraded.

Investigations in this study indicate that information technology tools are a fundamental mean in teaching architecture. Dynamic education and creating flexible environment is a result of using new educational technologies in electronic age. Flexible teaching space increased participation of students in theoretical and practical issues of architecture and accelerates the learning process. And students with more participation will be able to offer creative ideas.

Providing required infrastructure to use these tools for growth and strengthen the creativity and imagination power of architecture students is essential in architectural design. As in many architecture universities in the world has been used these systems to enhance the ability of their students.

Increasing funding for the optimal use of information and communication technology facilities, establishment of general education courses for students to recognizing the achievements of information and communication technology and create incentives for the use of these facilities, the creation of necessary facilities in order to expand the application of information technology in Schools with measures such as the proliferation of materials and equipment to create digital resources and scientific meetings using facilities such as computers, data projectors, - measures that should be taken.

Because the architecture is always connected with the latest technology and information, should not be missed the opportunity. In electronic learning in education of architecture field can beside physical presence in design studios, can use the Internet to communicate with different professors and students simultaneously and to participate several architecture colleges together and as well as has knowledge and benefit from new technologies used in the world.

\section{REFERENCES}

[1] Adibi, Ali Asghar, 1382, Space Journalism studios and their role in architectural education: Journal of Fine Arts Number 15, Spring, 1390, p 70.

[2] Hosseini, Seyed Asghar, Checking causal relationship of architectural thinking on improving the academic quality of education in architectural design. Fourth National Conference on Interior Design and Decoration in the conference hall of the International Commerce Chamber of Industries and Mines of Esfehan, Esfand, 1393. 
[3] Taghi Zadeh, Katayoon and Mahmoudi, Mohammad Mehdi, 1390. The role of the Internet and vitual learning in the process of architectural education: Proceedings of the Second Conference on Engineering Education with a view to the future, p; 58.

[4] Hojat, Isa, 1389, Architectural dictation, Tehran University press.

[5] Rahman Poor, Mohammad and Lyaghatdar, Mohammad Javad and Afshar, Ebrahim: 1388: A comparative study of the development of information technology in higher education: Emphasis on Iran: Journal of Education, Number 18.

[6] Shahamat, Fatemeh and Kadivar, Parvin and Farzad, Valiolah: cognitive styles and selfregulation in learning environment with computer assistance and comparison of it with the traditional environment, Journal of Education, Number 94.

[7] Fthian, Mohammad, 1378: The proposed model for assessing the level of intelligence required for buildings: Sharif Journal: Number 45. P: 1.

[8] Fthian, Mohammad and Mahdavi noor, Seyed hatam: 1389. Foundations and information technology management: University of Science and Technology: P 44-84.

[9] Farajollahi, Mehran and Zarif Sanayei, Nahid: 1388: Learning based on information and communication technology in higher education: Journal of Educational Strategies: Number 4: p 168-169.

[10] Kamel nia, Hamed, 1389: Grammar of design of learning environments: Sobhan publication: $\mathrm{p} 10$.

[11]Lawsen, Brayan: 1384. How designers think: (translate by Hamid Nadimi): Shahid Beheshti University Publication.

[12] Mahmoudi, Jafar and Nalchiger, Soroush, 1387: Investigation of challenges in development of smart schools in the country, Journal of Innovation Educational: Number 27.

[13] Mahmoudi, Mohammad Mehdi, 1390. Design of educational spaces based on flexibility: Tehran University Press: P: 130- 84- 83- 29.

[14] Mahmoudi, Mohammad Mehdi and Taghi Zadeh, Katayoun, 1388; Information technology and evolution process of engineering architecture education: Faculty of Engineering, Number 3: P: 160.

[15]Hosseini, Seyed Asghar and Loloie, Keyvan. Building Information Modeling of new technology and its application in digital architecture to achieve development and sustainable 
design. International Conference on Architecture, Building and Urban in Third Millennium, Tehran, culture house of Nyavaran, Mordad 94.

[16] Mazidi, Neda and Fatahi Abarghoveh, Yasaman, 1390: Identify chunky aspects of architectural spaces: Proceedings of the Fourth Symposium on Architectural Educati, College of Fine Arts, P: 31.

[17] Motlagh, Masoumeh and Behrooz nia, Parastoo, 1388: Checking the effect of information and communication technology on urban development: Bulletin of social Sciences: Second Number: P: 8.

[18] Aalam Rasi, Masoumeh, First National Conference of ideas and new technologies in architecture, Esfand, 1391.

[19] Mousavi, Setareh and Sharif, Mostafa and Rajaei Pour, Saeid and Babaie, Parinaz, 1390: Look at the process of course curriculum innovation in engineering education with an emphasis on information technology: Proceedings of the Second Conference on Engineering Education with a view to the future: P: 49.

[20] Vafa Mehr, Mohsen, Check the status of engineering education in Iran: Proceedings of the Second Conference on Engineering Education with a view to the future; P 20.

[21] H WA Hu, Paul Jen, "Examining technology acceptance by school teachers: A longitudinal study Information \& Management 41.227-241(2003).

[22] Kurt, Sevinc. (2009). "An analytic study on the traditional studio environments and the use of the constructivist studio in the architectural design education", World Conference on Educational Sciences 2009 Procedia Social and Behavioral Sciences 1(2009)401-408. , Academic Press, New York, 1998.

[23]F. Young, M. K. Cheng, S. M. Weng and K. L. Lee, "Nonlinear vibration analysis of a FGM plate with viscoelastic core", Proceedings of the 10 International Conference on Vibration Problems, Prague, Czech Republic, September5-8, 2011.

\section{How to cite this article:}

Hosseini S. A, Teimory S, Loloie K and Hamedani M. R. A. Architecture academic by information technologies utilization. J. Fundam. Appl. Sci., 2016, 8(3S), 1-15. 